\title{
Surveillance on Food Poisoning
}

\section{Juliana Andrew Obadele*}

Shehu Idris College of Health Science and Technology Kaduna, Nigeria

*Corresponding Author: Juliana Andrew Obadele, Shehu Idris College of Health Science and Technology Kaduna, Nigeria.

Received: August 29, 2019; Published: September 05, 2019

DOI: $10.31080 /$ ASPS.2019.03.0392

\section{Introduction}

Disquiet on the danger of food poisoning demand an article to create public awareness.

Food poisoning or contamination is the bait of bacteria or other toxins into what we eat, there by making us to fall sick that might cause death if immediate action is not taken.

Body

There are many means by which bacteria find their ways into our food.

- The animals we eat: Animals carry bacteria on their skins or hides and in their intestines.

- These bacteria such as salmonella, E. Coli clostridium perfringen are pathogenic that cause illnesses.

- Raw meat delivered to retail premises could be contaminated.

- Improper handling of food: The Physical, parts of human body such as the hands, sensory organs are usually exposed. They carry bacteria.

- Handling food without proper wash of hands can caused infection.

- $\quad$ Exposure of food without proper covering: In moving food items, from one location to another, or when exposed during processing, there is the tendency of the food being contaminated by heavy bacteria and other toxins in environment, even from the air around.

Precaution

1. Wash your hands thoroughly with water and soap ( warm or cold ) and let it dry before handling food.

2. Wash meat and other raw foods thoroughly before you cook.

3. Clean food premises 2 to 3 times daily.

4. Wash kitchen utensils thoroughly before use.

5. Avoid using your hands to touch sensory organs or other parts of your body, when handling or preparing food.
6. Do not sneeze directly, over food items or food.

7. Cover your head with scarf or cap while in the kitchen or other food premises.

8. Cover food properly.

9. Wash kitchen towels after cooking.

10. Avoid dust in the kitchen and other food premises.

\section{Volume 3 Issue 10 October 2019}

(C) All rights are reserved by Juliana Andrew Obadele. 